Pub. No. 360, 1925) dealing exhaustively with its activity in I9I4-I7 will take a high place in the literature of vulcanism. Lassen Peak began its life as a volcanic centre in early Neocene times, and has continued with diminishing violence down to the present day. It is now an old and dying volcano, for the explosive eruptions which began in r9I4 followed a period of apparent extinction which had lasted at least two centuries. Only once during its four years of activity were red-hot ejecta witnessed, and it seems to be completely established that high temperatures, such as are attained at Kilauea or Vesuvius, played no part in the eruptions. The first explosions broke through the snow-filled crater basin, and open cracks developed, down which the melted snow disappeared. A year later a lid or plug of dacitic andesite was forced up the vent to the level of the old crater-rim, and just failed to rise sufficiently to expose the underlying volcanic hearth. A plane of weakness was formed, however, on the north-east side of the cone, and through this two devastating horizontal blasts forced a passage. The adjacent valleys were stripped of all vegetation for four miles, but no fires were started save momentarily where a few dead leaves were ignited. Trees were merely scorched. Solid ejectamenta embedded themselves in the snow without melting any appreciable quantity. The great floods that followed a day or two later were most probably caused by the condensation of superheated steam from the volcanic cloud.

The outburst seems to have been assisted by an earthquake that weakened the structure of the volcano, and also by the flowing of water from melted snow down the first-formed cracks. But though this water must have participated in the tremendous steam-explosions that followed, it can scarcely have been an essential contributory cause, for the violence of the eruptions increased long after the snow had gone, and quantitatively it was inadequate to account for the enormous volumes of steam that escaped during the 300 or more explosions that afterwards occurred. Another source for the steam must therefore be postulated. The authors suggest that the gases responsible for the explosions were for the most part in solution in the crystallising magma beneath the crater, water being by far the most abundant ingredient of these volatile constituents.

It is now well known that a silicate magma can hold a considerable quantity of water in solution under appropriate conditions. G. W. Morey has pointed out (Journ. Washington Acad. Sci., vol. I2, p. 219, I922) that as crystallisation proceeds with falling temperature, the pressure of the volatile constituents increases at a rapid rate. This deduction from laboratory experience and thermodynamical reasoning goes far towards elucidating, not perhaps the entire problem of vulcanism as Dr. Day claims, but certainly most of the superficial phenomena of present-day volcanoes. The discharge of water during crystallisation must develop immense pressures when it takes place in a closed cauldron. The pressure may find relief in a single tremendous explosion, as in the case of Bandai San; or intermittently, as at Mt. Pelée or Lassen Peak, according to the rate of release of the water, and the roof conditions permitting or resisting its active escape. That the water-content of magmas before crystallisation is greater than that of crystallised rock is proved by the high percentage of water which is retained by obsidians and pitchstones.

The concluding sentences of Dr. Day's address summarise a long and consistently sustained argument: "Through all of these studies our conclusion seems to stand fast wherever it is applied, namely, that the outstanding factor in determining the character of modern vulcanism is the gas content of the crystallising magma. If this be mainly of steam released in a closed chamber, as at Lassen Peak, then only steam explosions are to be expected as the surface manifestation of the crystallisation of the magma below; if to the steam are added such chemically active gases as chlorine, sulphur, hydrogen and the hydrocarbons, then chemical reaction between these will be a sufficient cause of higher temperatures, and lava flows of the character well known at Vesuvius, Stromboli or Kilauea." ARTHUR HoLmes.

\title{
Diseases of the Hop.
}

A NUMBER of interesting communications have A recently appeared dealing with diseases of the hop. In particular a paper by E. S. Salmon and
W. M. Ware (Annals of Applied Biology, I925, I2, I2I) discusses in detail a downy mildew which was first found in Europe in. I920 at the experimental hop gardens of Wye College. Since that year the intensity of the disease has been increasing rapidly, and it may become a serious factor in hop production in the future.

Previous to 1920 the disease was observed in Japan in roo5 (Pseudoperonospora Humuli (Miyabe and Takah.) Wils.) and in the United States in I909, and there appears to be little doubt that the three diseases are identical. In 1923 the opinion was expressed that the fungus causing the disease had been imported into Great Britain from one of the countries mentioned, but subsequent work has led to the conclusion that it is indigenous. The downy mildew which is common to the nettle, Peronospora Urtice (Lib.) de Bary, has been found to differ only as regards the size of the oospore from that occurring on the hop, and cross-inoculation experiments have led to the suggestion that the fungus may be transferred from one to the other. This is supported by the fact that infected nettles have often been found in close proximity to infected hops. Assuming then that the fungus from the nettle has found a new host, it would seem that the chance of infection becomes greater in a wet than in a dry season. This might account for the great increase in infection during the particularly wet season of 1924 . On the other hand, a process of evolution may be taking place in which the hop is being infected by new forms of the downy mildew of the nettle, and in this case the prospect is rather more serious. Consequently the results of investigations during the 1925 season will be awaited with great interest.

It may also be mentioned that a similar disease has recently been noted for the first time in Germany, and as the nettle mildew is known to occur in the hop-growing districts of that country, some light may be shed on the problem from this quarter.

The disease is characterised by the appearance on the hop leaf of reddish-brown angular spots. Under the microscope these can be seen to consist of hairlike growths, which differ from ordinary hop mildew in that they are branched instead of unbranched. The branches bear conidia which drop off and spread the disease by germination in the presence of water. The hop cones may also be attacked, in which case the whole cone may turn brown and wither.

These symptoms must not be confused with those arising as a result of the "browning of cones" disease which in recent years has attacked hops on the Continent. This disease is also characterised by 
a shrunk epidermis which contains a reddish-brown substance, and has been ascribed by Wagner (Tageszeit. Brau., I924) to the exceptionally unfavourable weather conditions of I924, rather than to a particular organism. P. Lindemanns (Pet. Jour. du Brass., $1925,33,189$ ) has stated that the disease was due to lack of nourishment of the cones. This was a result of the insufficient supply of sap, the transpiration being checked by the excessive humidity of the atmosphere. Thus, when the rows of hops had been planted in the direction of the prevailing winds, the disease was less marked than in the case of plants from damp and low-lying parts.

J. G.

\section{University and Educational Intelligence.}

CAMrRidge.-Mr. R.E. Priestley has been appointed Assistant Registrary with the duties of Secretary to the Boards of Examinations and Research Studies. Mr. Priestley was a member of two Antarctic Expeditions ; he entered the University as a research student in geology in I9I 3 ; became a fellow of Clare College in I 923 and has been secretary to the Board of Research Studies for two years.

Two lists of successful candidates in the recent scholarship examinations have been published. An analysis of the awards of open scholarships and exhibitions shows that 35 are for natural science, 42 for mathematics and I $_{3}$ for other subjects-.classics, history, languages, etc. A further point of interest lies in the distribution of the successful candidates among the schools. It is often nowadays no easy matter to decide whether any place of secondary education is a "public school" in the generally accepted sense of the term. It is possible, however, to draw up an arbitrary list which will include those schools which the majority of educated people would call " public schools." The present writer has ventured to construct such a list, and has grouped the new scholars and exhibitioners according to it. The following figures have been obtained.

$\begin{array}{lcccc} & \text { Nat. Sci. } & \text { Math. } & \begin{array}{c}\text { Other } \\ \text { Subjects. }\end{array} \\ \begin{array}{l}\text { From Public Schools } \\ \text { From other Secondary }\end{array} & \text { II } & 2 \text { I } & 65 \\ \text { Schools . } & & 24 & 2 \text { I } & 48\end{array}$

Any deductions made from these figures are liable to severe criticism, but three hypotheses suggest themselves :

(I) The public schools divert the majority of their best scholars in directions other than scientific ones.

(2) The teaching of " other subjects" in the public schools is superior to instruction in them.in the other schools.

(3) The teaching of science in other schools is generally superior to that in the public schools.

It is commonly believed in Cambridge that (3) is certainly partially correct in many cases. Perhaps it is time that the public schools gave the matter further thought.

ACCORDING to the report recently issued by the Secretary of the Rhodes Trust, the number of Rhodes Scholars in residence during the year 1924-I925 was I 85 , of which 96 were from the British Empire and 89 from the United States ; 63 took up their scholarships for the first time. The present academic year started with 185 scholars in residence. From the table showing the distribution among subjects during the past year, it appears that $4^{8}$ were taking natural science and medicine and 2 mathematics. Five Rhodes Scholars were awarded the degree of D.Phil. three of them being natural science students. Reference is also made to distinctions gained by former Rhodes Scholars, among whom are R. B. Brode, awarded a research fellowship by the National Research Council of America; H. W. Florey, appointed to a Rockefeller medical fellowship; and E. P. Hubble, who was awarded half the American Association for the Advancement of Science Prize for I924 for his researches on nebulæ. Notice was received during the year of no less than 33 new books by Rhodes Scholars, of which only 4 have a bearing on science. The scholarships are to continue to be of the annual value of $400 l$. each. A site has been purchased at Oxford for the erection of a building to be known as "Rhodes House," which will be the residence of the Oxford secretary and will contain a library and a hall for the annual dinners of the Trust. Information as to the scholarships may be obtained from the offices of the Trust, Seymour House, Waterloo Place, London, S.W.I. In the United States application may be made to President Aydelotte, Swarthmore College, Swarthmore, Pennsylvania; in Canada to Mr. J. M. Macdonnell, National Trust Company, Limited, Montreal, P.Q.; in Australia to Dr. J. C. Behan, Trinity College, Parkville, Victoria; in South Africa to Mr. P. T. Lewis, Court Chambers, Keerom Street, Cape Town.

Apprentices in H.M. Dockyards have to attend school for a certain number of hours each week, and any one who knows the Dockyard schools and the instructors in them is not surprised at the successes of the students, for no better scientific and technical education for youths is given anywhere in Great Britain. As, however, the apprentices are educated at the public expense with the view of their becoming shipwrights or fitters in the Dockyards, and as they have many decided advantages over students in technical schools outside, it seems scarcely just that they should be able to use these advantages to secure scholarships intended for science students generally. Judging from the list, just issued by the Board of Education, of successful candidates for Royal Scholarships and Free Studentships, and from the latest list of awards of Whitworth scholarships, there is little prospect of success for any candidate who has not been educated in a Dockyard school, particularly for scholarships in engineering subjects. Thus, there were seventy-one competitors for Group A (Engineering) for Royal Scholarships and Free Studentships in the I925 examination, and each of the eleven successful candidates was a Dockyard apprentice. In the other groups--physics, chemistry, biology, and geology - all the successful candidates were from schools and colleges not in the Dockyards. Nearly all the Whitworth scholars in the last list were from the Dockyard schools, and so it has been for several years. This must be discouraging to teachers and students in other technical schools and colleges, and we suggest that the Board of Education might well give attention to the matter with the view of arriving at a more equitable adjustment of the awards. It was never intended that Royal and Whitworth Scholarships should be a special reserve for students in such institutions as H.M. Dockyards, where exceptional opportunities of preparing for them are enjoyed, both as regards the advantage of being given school time in working hours and as regards the practical and theoretical instruction afforded.

NO. 2932, VOL. I I 7] 